\title{
Preparing the Dietetic Workforce of the Future - Developing Innovative Placements in Social Care Settings
}

\author{
Myra Mackenzie \\ Robert Gordon University, United Kingdom \\ Evelyn Newman \\ NHS Highland, United Kingdom
}

\begin{abstract}
Practice placements are key to the training of an allied health professional, supporting the integration of theoretical and practical knowledge, allowing the development of key skills and enculturation to a professional role. Practice placements in dietetic pre-registration training have largely focussed on clinical/health care settings, with the students based in dietetic departments. Current developments in integrated health and social care provision in the United Kingdom mean there is a compelling need to develop a workforce equipped to work across sectors to effectively support people's nutritional needs. Against this background, a partnership group of healthcare and managerial professionals, representing NHS Education for Scotland (NES), NHS Highland $(\mathrm{NHSH})$, a private care home group based in the North of Scotland and Robert Gordon University worked together to pilot and develop a model for the placement of student dietitians within social care settings (initially care homes). This novel approach embeds students in a social care setting for part of their placement rather than having them based within a dietetic department. The placements were positively evaluated and widely shared via Alled Health Profession (AHP) blogposts and in publications such as the Care Inspectorate newsletter, and other Scottish Health Boards are now developing local models of dietetic social care placements. There is a recognition that practice placement models should prepare the dietitians of the future for working beyond NHS environments, and that alternative models of placement should be explored from the perspective of raising the profile of the profession and ensuring sustainability of placement provision.
\end{abstract}

Keywords: dementia; nutrition; social care

${ }^{\star}$ Corresponding Author: Myra Mackenzie, School of Pharmacy and Life Sciences,

Robert Gordon University, Garthdee Road, Aberdeen, AB10 7QE United Kingdom

Email:m.mackenzie3@rgu.ac.uk

Journal URL: http://e-learning.coventry.ac.uk/ojs/index.php/pblh

Mackenzie, M. and Evelyn Newman (2017) 'Preparing the dietetic workforce of the future - Developing innovative placements in social care settings'. International Journal of Practice-based Learning in Health and Social Care, 5 (1), 65-76

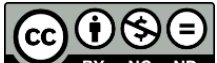

BY NC ND (c) 2017 Myra Mackenzie and Evelyn Newman. This Open Access article is distributed under the terms of the Creative Commons Attribution Attribution-Non-Commercial No Derivatives 4.0 International License (https://creativecommons.org/licenses/by-nc-nd/4.0/ ), which permits unrestricted non-commercial use, distribution, and reproduction in any medium, provided the original work is properly cited and is unaltered. 


\section{Background}

Successful completion of a practice placement is an integral element of pre-registration dietetic student training, and students in the United Kingdom (UK) usually undertake three practice placements over the course of their studies. The Health and Care Professions Council (HCPC) is the regulatory body for the profession, and broadly specifies the requirements for practice placements on pre-registration programmes (Health and Care Professions Council 2014). While these standards encompass key areas, from supervision to duration and range, they are of necessity high-level in their approach, as they pertain to all the allied health professions and their students. Therefore the onus for ensuring practice education requirements are met falls on the professional bodies, and are clarified within their curriculum frameworks. The British Dietetic Association (BDA) therefore, within its Curriculum Framework, sets the profession-specific guidance for dietetic education, including practice placement provision. Currently, in the UK, students are required to complete not less than 1000 hours of practice, with at least one placement of sufficient length to enable continuity of learning and to demonstrate consistency of performance and case load management in a clinical setting (British Dietetic Association 2013). Prior to the publication of the British Dietetic Association's 2013 Curriculum guidance (British Dietetic Association 2013), the emphasis of practice placement was on clinical/health care, whether this was delivered in an NHS acute or community setting such as domiciliary visits or a GP clinic. The BDA guidance states that "the sites of the practical placement should reflect the breadth and diversity of working environments of entry level dietitians... [and] include some time in acute and primary care dietetics" (British Dietetic Association 2013: 15). This statement takes account of and recognises the fact that dietitians may work in a variety of settings, but does not specify what those settings are or how long a student is expected to spend in each of them.

Importantly, it also recognises that although overarching responsibility for supervision and assessment of the practice placement will lie with one designated individual, there is scope for the involvement of other staff (dietetic and non-dietetic), and arm's length supervision is not precluded (British Dietetic Association 2013). Indeed there is recognition from within the profession that this may be the preferred supervisory model in emerging practice education sectors (British Dietetic Association 2015a, 2015b).

One of the initial drivers for the pilot placements in social care settings was the publication of the Scottish Government's 2020 vision, which sets out the expectation that, by that year, everyone will be able to live longer healthier lives at home, or in a homely setting, and that health and social care systems will be fully integrated (Scottish Government 2012). Since the publication of the initial document in 2012, the move towards full integration of health and social care in Scotland has gathered momentum, with the legislation to implement this coming into force in 2016, with the establishment of partnerships between the NHS and local council care services in each area. In total, 31 local partnerships have been established and they manage almost £8 billion of health and social care resources (Scottish Government 2016). The expectation is that care will be provided nearer to home for all, and that the staff involved in delivery of that care will be doing so in a primary care setting. Currently, dietitians provide input to care home settings based on referrals for therapeutic advice via general practitioners and other healthcare staff, and may also be involved in providing education and training to care home staff on a more ad hoc basis. The initial care home placements were developed in order to fit with the Scottish Government's expectations, and to ensure that care is delivered where the clients are, rather than expecting clients to come to the care provider.

The other driver for exploring the feasibility of social care placements lay in ensuring a sustainable approach to the provision of practice placements. Over the past few years, there have been persistent and increasing issues across the UK with sourcing practice placements to meet demand, and this is exacerbated when students defer placement or have to repeat an element of practice placement.

A 'role emerging placement' can be defined as one which "occur(s) at a site where there is an established... role" (College of Occupational Therapists 2006:1) and could therefore be a 
valuable means of exposing students to emergent working practices in new and diverse settings. NHS Education for Scotland has described these placements as 'contemporary' and recognises that they are about gaining valuable practice learning experience while developing capacity and capability in the care sector. To date, twelve placements have been carried out in social care settings (either care home or care at home). These have been at different stages of the dietetic training programme, from second to fourth stage, and have involved students from all three Universities in Scotland proving dietetic pre-registration training. Currently, in Scotland, students undertake 4 weeks of practice placement in second stage, split between campus and practice placement sites (Practice Placement A). There are two pass/fail competencies in Practice Placement $A$ relating to professionalism and communication skills. They then undertake two twelve-week practice placements in (Practice Placements $\mathrm{B}$ and $\mathrm{C}$ ) and begin to apply theoretical knowledge gained at University and develop the skills needed to practice as a dietitian. At all stages, students are assessed via a portfolio of evidence, and assessment is integrative, multi-modal (i.e. formative, continuous and summative) and uses a range of assessment activities (i.e. observation, case studies, reflection etc.) (Lennie and Juwah 2010). Across the three practice placements, students move according to Bloom's taxonomy, from knowledge to synthesis via a process of experiential learning (Bloom 1956). At the end of Practice Placement C, students are expected, as entry-level dietitians, to be able to work as autonomous practitioners within a wide-ranging sphere of influence, using evidence-based practice.

This article is intended to be a reflective account by a Higher Education Institution (HEI) representative and NHS practice educator of the process involved in piloting dietetic undergraduate placements in care home settings.

\section{Planning the placements}

Initial scoping discussions were held between all partner agencies, including the NHS practice education facilitator, nutrition advisor for care homes (EN), Care Home Inspectorate, HEI representative (MM), NHS Education for Scotland and the care home manager. The care home identified for the initial placement experiences was chosen as a positive learning environment, with motivated staff and management who were willing to support a student. A number of suitable competency-linked activities were discussed and agreed as being suitable start and finish tasks, which could be achieved in a care home setting, with limited dietetic supervision. These included a staff-related study of hydration, an audit of nutrition care plans, trialling a new audit tool for $\mathrm{NHSH}$, and working with the care home staff (including the cook and activities coordinators) to develop nutrition focussed projects.

The development of the students' timetables took account of the need for initial orientation and induction to the community dietetic team base. For the B and C placement students, it also had to build in a four-week consolidation period towards the end of the twelve-week placement. The students therefore spent one or two separate days a week across five consecutive weeks in the social care setting, identified as most suitable for the care home. This is in line the guidance from the BDA for contemporary and innovative models of placement, which suggests that these should be incorporated into the overall programme rather than used in isolation to provide a robust and holistic training package (British Dietetic Association 2015b). For the A placements, the students spent one day a week during the two-week placement away from the dietetic base in the social care setting.

The nutrition advisor for care homes (EN) spent a day with the students during their initial induction week, having developed and delivered an introductory care homes' tutorial, followed by an on-site visit to the care home. This allowed the students to understand the differences between the clinical model of care in the NHS and the person-centred, social model of care, for care home residents. They had an opportunity to meet the care home staff, view the care home environment and talk with some residents, discuss practical aspects of their time there, such as staff meal times, uniform-changing, and where to carry out paperwork. 
An important way in which this placement model differed from more traditional models lay in supervision, which is usually either on a one-to-one basis or as a peer-assisted learning (O'Connor, Cahill, and McKay 2012). However, in this model, there was no on-site dietetic presence. Students had practical supervision from care home senior staff, weekly supervision reviews from the base trainer in the clinical setting and on-site visits from both the clinical tutor and the care home nutrition and dietetics advisor throughout their placements. Regular weekly phone and email contact with the nutrition and dietetics advisor and the $\mathrm{HEl}$ was also maintained. Because of the nature of the supervision, the students were not able to give dietetic advice to any residents, but focused instead on project work and working with other staff members to practically support residents' nutritional requirements.

\section{The student perspective}

The first student to carry out this placement shared her experience extensively through articles in journals such as Care News (Spring 2015), Dietetics Today, NHS Highland Highlights, the care home newsletter, the AHP blogspot, and through participation in a Teaching and Learning conference hosted at Robert Gordon University. Her perspective on her feelings before and after the placement were shared in a slide which contrasted her confidence level before and after her social care placement.

Before undertaking the placement, the student said that she was unsure of the relevance of the placement, nervous as she did not know what to expect, unsure of a care home setting, and felt isolated as 'I was going to be doing this by myself'.

Afterwards, she said "I found the experience so worthwhile. The placement got such great comments from the care home manager and the care staff, and during my time there the residents seemed to really enjoy the additional communication with me, I benefited from this because of such positive feedback and the successes of the projects I completed during my time in the care home."

\section{Rabbit stew, anyone?}

One of the activities carried out by the student and the activities coordinator involved talking about the residents' memories of childhood mealtimes, special occasions and their favourite foods. The student said "The results of this exercise were astonishing, as they rekindled many memories of family mealtimes and favourite foods. One resident, normally a very quiet lady, became actively involved in the conversation, articulating herself really well. She became animated when we were talking - it was wonderful to see."

The residents were asked to create a favourite menu which the care home cook prepared for a themed day; the final menu was Scotch broth and rabbit stew followed by clootie dumpling (clootie dumpling is a fruit pudding boiled in a cloth or 'cloot', and often served on birthdays or at Christmas).

Feedback from residents and their families and carers was overwhelmingly positive, with comments such as:

'We always got clootie dumpling at birthdays and if you were lucky, you got a silver threepence';

'I was brought up on rabbits; they were more tasty before the war'; and

'Clootie dumpling was the best part'.

These quotes reflect pleasurable experiences and memories associated with food. 
One resident's daughter picked up on the role it played in memory recall. 'My mother was telling me about when she was little when her mother used to go to the butcher and get a rabbit for a shilling. She'd then sell the rabbit skin to a man who came round the houses; there's no way she'd have remembered that normally.'

The success of this activity led to the student, carrying out her Honours project in a care home setting, to develop further the theme of the reminiscence meal into a project investigating whether engaging people with dementia in conversations about food and food memories could improve nutritional intake. This is important, as malnutrition is prevalent in the older age group, particularly so in people with dementia (Saka et al. 2010, Roqué, Salvà, and Vellas 2013).

For this innovative project, the student worked with the local museums service, who had curated themed collections for use with people with dementia and their carers, and had provided artefacts and printed material to prompt discussion. This pilot study provided preliminary evidence that talking to people with dementia about long-buried food memories can have a positive effect on food intake, measured by a food intake chart, and in particular on energy intake. This project was runner-up in the 2015 Scottish Dementia awards in the 'most innovative partnership' category and has been shared extensively via the AHP blogspot and Care News.

Since this placement and project, twelve placements have been carried out in social care settings (either care home or care at home). These have been at different stages of the dietetic training programme, from second to fourth stage, and all placements from A to C. In addition, two students have carried out their Honours projects in care homes.

\section{Evaluation}

All placements were evaluated following the model developed by NHS Education for Scotland for occupational therapy student placements carried out with the Fire Brigade (NHS Tayside and Scottish Fire and Rescue Service 2012) and Dance and Movement Psychotherapy students in Care Homes (NHS Education for Scotland 2012).

This used semi-structured interviews and student stories prompts to encourage participants to consider their involvement with the pilot pre-, during and post-placement.

The evaluation forms including sample questions were emailed to all in advance of face-to-face or telephone semi-structured interviews. They were designed to capture the views of the students, practice placement co-ordinator, NHS Education for Scotland via the AHP practice education lead, HEI representative, and care home and care agency staff. The questions were structured into three main areas - pre-placement, during and post-placement - and sought opinions on the placements from all stakeholders. Questions related to student preparedness for placement, information received prior to the placement, level of support during placement, the learning environment, the student's role, the value of the placement, and suggested changes for future placements.

\section{Findings}

\section{Pre-placement}

There was a general sense from all stakeholders that the placements had potential and were worth exploring in terms of feasibility and usefulness. Students could see how the experience would help future employment prospects, and welcomed the opportunity to experience a different setting.

Key words used by students to describe their feelings prior to placement were: apprehensive, hopeful, excited, positive, delighted, innovative, and interesting. 
Despite some anxiety that time was being taken away from clinical activity in hospital settings, the placement coordinator was keen to try and work the placement into the timetable.

Everyone agreed that the initial planning work, which comprised meetings to discuss and share perspectives, ideas and opportunities for the pilot, had allayed any fears that they had about the placement going ahead or succeeding.

Additionally, there was a feeling of shared excitement in working as a partnership, doing something so new and innovative, with mutual support and commitment. The personal connection certainly helped with the sense that each person felt everyone had a 'can do' approach to making it a success.

\section{During the placement}

Overall the students felt well supported during their time in social care placements, despite there being no on-site dietetic presence. Students consistently reflected that the pre-planning and initial induction had given them the confidence to plan their time autonomously and to enable them to 'hit the ground running'. For example one student was able to independently carry out a Malnutrition Universal Screening Tool ('MUST') care plan audit of all residents' case notes on her first day, and another started a short audit of fluid intake of residents and carers.

A half-way review of the placement by the partnership members allowed sharing of the various elements of work and gave an opportunity to highlight areas of concern; none were reported or discussed at this stage.

Key words were: well organised, welcoming, structured, helpful, homely.

\section{Post placement}

All stakeholders agreed that the placement offered significant opportunities to gather sound, objective evidence measured against the core competencies required by the BDA. Each observed, however, that it would be possible to evidence even more, as the possibilities for doing so were greater than originally imagined. Specifically, students stated that learning outcomes centred around professionalism, consent, communication, assessment of nutritional needs, anthropometry and observation are areas of practice which could be comfortably accommodated in a care home setting.

The students reflected that carrying out a case study in a care home setting offered an opportunity to get to know the resident more informally, in a more relaxed home setting while having the time to complete the work without the potential for the case study participant being moved, as so often happens in hospital settings.

Students commented that they had a better understanding of social care processes and services, and that they believed that this would be helpful in future employment.

The care home staff valued the students' input, and commented that they would be putting into place action plans to support nutritional care, and that the placements would inform better care delivery for residents.

Key words were: professionalism, communication, time management

All partner agencies also agreed that the maturity, hard work and organisation of the students undoubtedly helped ensure the success of these placements and enabled them to overcome the challenges that occurred along the way. 


\section{Challenges during the placement}

Participants noted some challenges but all felt the lessons learned from these could alleviate these recurring in future:

The care home placement was initially timetabled alongside a day out per week on a health improvement project, which meant that the student was away from the hospital base for three days a week for five weeks. With hindsight, it was felt that the timetable could have been structured differently and the health promotion activity could have been delivered at a different time, so that the student was not away from the clinical setting for such an extended period.

There was a sense, amongst some dietetic staff, that the time out on placement in a care home setting had a detrimental effect on the clinical experience of hospital work and on the capacity to gather evidence to demonstrate competencies. This was largely because they did not fully understand how many learning outcomes were actually being delivered from the off-site placement but also reflected some on-going pressure within the team, linked to staffing shortages.

\section{Discussion}

There is no doubt that practice placement in dietetic training is a vital component in the development of professional skills and competencies (Lennie and Juwah 2010). However, beyond these, development of care and compassion, and advanced communications skills are also core, underpinning elements of any health care professional (Cornwell and Goodrich 2009). The social care placements enabled the students to take the time to develop relationships with residents, relatives, care staff and cooks.

The placements described have facilitated the development of some of these 'softer' skills, allowing as they did the students to spend more time with care home residents in a nontherapeutic, personal relationship. This supported the shift in role perception and the government-driven move away from a traditional medical model of care, which is illnessfocussed and institution-based to a more holistic and person-centred model, with a focus on optimising health (Scottish Government 2012). Beyond this, having a dietetic student embedded in a working social-care setting enabled the student(s) to develop confidence, leadership skills and stronger professional identity. The autonomy offered by the model of arm's length supervision facilitated the students in their own ontological development, rather than, as is the case in more traditional placements, modelling themselves on supervisors (Clarke et al. 2014).

The evaluations also suggested that the placement hosts (i.e. the care homes and the home care agency), the service users and their families also valued the presence of the students, as described in occupational therapy students undertaking role-emergent placements (Thew et al. 2011). The student reflections suggested that they gained an insight into the roles of others (e.g. nursing and care staff) as well as an appreciation of their perspective on clients' home care.

Bacon, Williams, and Grealish (2015) carried out a questionnaire-based investigation with education providers into current practice in dietetic pre-registration placements in non-hospital settings in Australia, and suggested that aged-care facilities provide an appropriate care setting for student dietitians to demonstrate several core key competencies. In particular, they highlighted that within this setting, competencies around identification of nutritional needs could be achieved, with other competencies being demonstrated in other settings. This supports the design we used in our placement delivery, with a blend of placement settings providing students with different experiences. Lordly and Taper (2008) suggest that there is the potential for risks and benefits with placement delivery exclusively based in one environment, while Ash and Philips (2000) stated that different settings value different competencies to varying degrees, and this should be reflected in placement delivery. 
Bacon and colleagues also found, as we did, that acute or clinical placements are often perceived as the 'gold standard' by clinicians, and by extension placements in social care or long-term care settings are somehow less relevant or valid (Bacon, Williams, and Grealish 2015). A systematic review of medical undergraduate placements in non-hospital-based areas (Crampton, McLachlan, and Illing 2013) reported similar concerns, but also highlighted that students exhibited a more holistic approach to health care and had enhanced interpersonal and communication skills, with no diminution in clinical proficiency. For students following the Scottish programme, social care placements sit comfortably with Practice Placement ' $A$ ', which is delivered early in the training programme, with the assessed competencies around communication and professionalism.

An issue perhaps of more concern is highlighted by Lordly and Taper's (2008) suggestion that there is an inherent and unrecognised bias to working in long-term care. This is supported by work carried out by Kaempfer, Wellman, and Himburg (2002: 201), in which dietetic students described older adults as "set in their ways, glad to retire ... depend[ent] on others". It is also consistent with other studies in which older adults were described as being institutionalised, lonely, bored and isolated (Williams, Lusk, and Kline 1986). Moreover, students placed working with older adults as a low priority, and demographics across the world would suggest that we live in a time of population ageing, with implications for the delivery of health care (United Nations 2015).

Health care professionals of the future will need to be both well prepared and knowledgeable to deal with the needs of an older population, and education providers will have to take account of this. Lee et al. (2008) evaluated a guided experiential assignment with nutrition and dietetic students and found that students' beliefs, values and self-efficacy towards older people improved significantly after conducting a self-care intervention with them. In particular, Lee et al.'s study found that the experiential session significantly challenged student stereotypes of older adults; they suggest that 'attitudinal dissonance' is responsible in part for this - where students are exposed to experiences and people who challenge their original beliefs. These findings are consistent with those found in other studies. Rasor-Greenhalgh, Stombaugh, and Garrison (1993) similarly found that conducting nutritional assessments with older adults improved students' attitudes towards that age group. Therefore, having placements in socialcare settings with a focus on older adults will better prepare the workforce of the future for working with this population.

The benefits of these placements are not confined to students; our study also highlighted the potential benefits for residents and service users, in that staff valued the students' input and made changes to meal delivery and nutritional care in their organisations. To date there has been no work carried out in this area, and it may be that the dietitian being 'embedded' in the organisation leads to a more collaborative and holistic approach to care delivery.

\section{Limitations}

It is important to recognise that the strengths of this type of placement may also be viewed as limitations, depending on the student and the particular circumstances (Smith, Cornella, and Williams 2013). While the students who undertook these placements valued the opportunity to work more independently, this may be a reflection of them as individuals, rather than the general body of students. Some students may be daunted by the expectations of working more autonomously, and, rather than supporting a 'professional way of being', potentially weaker students may struggle and need more support in these placements. It has been suggested that placing less confident students in a novel placement could be 'unethical' (Sullivan and Finlayson 2000) as they may not be able to achieve the required learning outcomes within the limited clinical contact time. The evaluations we carried out suggested that for some clinical supervisors this was a real concern. However, the evidence the students collected for their portfolios was clearly mapped against learning outcomes, showing that they were able to meet their objectives in the time available. To a certain extent this concern can be mitigated by 
planning the placement carefully, and ensuring that the student feels adequately supported and knows the arrangements for supervision and support.

The evaluation also emphasised the importance of the preparatory work that was carried out prior to the initial placement. This included site visits, tutorials, orientation and induction days, and was therefore a significant commitment by the team to ensure the success of these placements. Previous authors have supported the view that this investment of time is essential to the success of the placement (Thomas and Rodger 2011).

Perhaps the most significant challenge was around ensuring sufficient 'buy-in' from supervisory staff, some of whom believed that the more medical- and illness-focussed traditional placement model was more useful to the student. This again is in keeping with previous literature (Kirke, Layton and Sim 2007), and in our experience these anxieties were mitigated by sharing the learning outcomes and experiences of the students who had undertaken these placements. It should also be noted that the sample size in this project was small and drawn from dietetic students in Scotland; it does however start a dialogue on the role of social care placements in pre-registration dietetic education.

\section{Summary}

One of the most striking findings from developing these contemporary placements was the dearth of literature in dietetic practice education, resulting in much of the supporting evidence drawn from the literature deriving from other health professional students. No studies were found in UK dietetic pre-registration training which evaluated role-emerging placement models, and none looked at the experiences of the students, practice placement educators, service users or host sites. Developing placements in social-care settings delivered much more in terms of personal and professional development than was originally anticipated, and allowed the students to experience and reflect on differences between clinical and social models of care. Stronger cross-sector links were forged and a greater level of understanding about the potential for dietetic placements was achieved. The general consensus was that it had been a largely positive experience for everyone concerned, including the staff, residents, service users and their families. The profile and value of dietitians' work and nutrition generally, in social care settings, have been championed through this innovative approach and recognised by many more people. More dietitians will be required to deliver services in health and social care settings in the 2020 vision for the NHS in Scotland, and there is therefore merit in developing these models of placement further, and in conducting further research in the area.

Ethical approval was sought and given by the School of Pharmacy and Life Sciences Ethics Review Committee, Robert Gordon University. Confidentiality and anonymity was maintained at all times for study participants (residents and their families, staff), and all data was stored and handled in accordance with the School of Pharmacy and Life Sciences standard operating procedures.

Permission was sought and granted to use anonymised quotes from service users, staff and students.

\section{Acknowledgements}

The authors would like to thank all of the students and care home staff for their willingness to engage with these innovative placements. We would like to thank the Parkland Group of Care Homes (and in particular Denise Scott, Manager) and Highland Home Carers for their enthusiasm, and Aberdeenshire Council Museums Service for the loan of their resources. Emma Pasieka, Practice Educator, and Kerrie McLean, Practice Education Facilitator, were instrumental in ensuring that these placements were fully supported. 


\section{References}

Ash, S. and Phillips, S. (2000) 'What is dietetic competency? Competency standards, competence and competency explained'. Australian Journal of Nutrition and Dietetics, $57,147-153$

Bacon, R., Williams, L., and Grealish, L. (2015) 'Aged care facilities and primary health-care clinics provide appropriate settings for dietetic students to demonstrate individual case management clinical competence'. Nutrition and Dietetics, 72, 54-62 https://doi.org/10.1111/1747-0080.12156

Bloom, B.S. (ed.) (1956) Taxonomy of Educational Objectives: Vol. 1. The Cognitive Domain. New York: David McKay

British Dietetic Association (2013) A Curriculum Framework for the Pre-Registration Education and Training of Dietitians. Birmingham, UK: The British Dietetic Association

British Dietetic Association (2015a) A Guide to Innovative Practice Education Placements. Birmingham, UK: The British Dietetic Association

British Dietetic Association (2015b) Innovative Practice Education Placements: Case Studies. Birmingham, UK: The British Dietetic Association

Clarke, C., Martin, M., Sadlo, G., and de Visser, R. (2014) 'The development of an authentic professional identity on role-emerging placements'. British Journal of Occupational Therapy, 77 (5), 222-229 https://doi.org/10.4276/030802214X13990455043368

College of Occupational Therapists (2006) Developing the Occupational Therapy Profession: Providing New Work Based Learning Opportunities for Students. London: COT

Cornwell, J. and Goodrich, J. (2009) 'Exploring how to ensure compassionate care in hospital to improve patient experience'. Nursing Times, 105 (15), 14-16

Crampton, P.E, McLachlan, J.C., and Illing, J. (2013) 'A systematic literature review of undergraduate clinical placements in underserved areas'. Medical Education, 47, 969978 https://doi.org/10.1111/medu.12215

Health and Care Professions Council (2014) Standards of Education and Training. London, UK: $\mathrm{HCPC}$

Kaempfer, D., Wellman, N., and Himburg, S. (2002) 'Dietetic students' low knowledge, attitudes, and work preferences towards older adults indicate need for improved education about aging'. Journal of the Academy of Nutrition and Dietetics, 102,197-202 https://doi.org/10.1016/S0002-8223(02)90048-9

Kirke, P., Layton, N., and Sim, J. (2007) 'Informing fieldwork design: Key elements to quality in fieldwork education for undergraduate occupational therapy students'. Australian Occupational Therapy Journal, 54, S13-S22 https://doi.org/10.1111/i.14401630.2007.00696.x

Lee, S-Y., Hoerr, S.L., Weatherspoon, L., and Schiffman, R.F. (2008) 'Nutrition students improve attitudes after a guided experiential assignment with older adults'. Journal of Nutrition Education and Behaviour; 40, 279-287

https://doi.org/10.1016/i.jneb.2007.09.011 
Lennie, S. and Juwah, C. (2010) 'Exploring assessment for learning during dietetic practice placements'. Journal of Human Nutrition and Dietetics, 23 (3), 217-223

Lordly, D. and Taper, J. (2008) 'Assumptions lead to the devaluation of dietitian roles in longterm care practice environments'. Journal of Allied Health, 37 (2), 78-81

NHS Education for Scotland (2012) More than a dancer: a practice placement pilot with dance movement psychotherapy students. [online] available at:

http://www.nes.scot.nhs.uk/education-and-training/by-discipline/allied-healthprofessions/resources,-publications-and-useful-links/publications/more-than-a-dancercontemporary-allied-health-professional-placements-in-care-homes.aspx [30 June 2017]

NHS Tayside and Scottish Fire and Rescue Service (2012) Working Together to Prevent Fire Deaths and Accidents. Dundee, UK: NHS Tayside \& Scottish Fire and Rescue Service

O'Connor, A., Cahill, M., and McKay, E. (2012) 'Revisiting 1:1 and 2:1 clinical placement models: Student and clinical educator perspectives'. Australian Occupational Therapy Journal, 59 (4), 276-283 https://doi.org/10.1111/j.1440-1630.2012.01025.x

Rasor-Greenhalgh, S., Stombaugh, L., and Garrison, M. (1993) 'Attitudes changes of dietetics students performing nutritional assessment on healthy elderly'. Journal of Nutrition for the Elderly, 12, 55-64 https://doi.org/10.1300/J052v12n04 06

Roqué, M., Salvà, A., and Vellas, B. (2013) 'Malnutrition in community-dwelling adults with dementia (NutriAlz trial)'. The Journal of Nutrition, Health \& Aging, 17 (4), 295-299 https://doi.org/10.1007/s12603-012-0401-9

Saka, B., Kaya, O., Ozturk, G.B, Erten, N., and Akif Karan, M. (2010) 'Malnutrition in the elderly and its relationship with other geriatric syndromes'. Clinical Nutrition, 29 (6), 745-748

Scottish Government (2012) AHPs as Agents of Change in Health and Social Care. The National Delivery Plan for Allied Health Professions in Scotland, 2012-2015. Edinburgh, UK: Scottish Government

Scottish Government (2016) Health and Social Care Delivery Plan. Edinburgh, UK: Scottish Government

Smith, Y.J., Cornella, E., and Williams, N. (2013) 'Working with populations from a refugee background: An opportunity to enhance the occupational therapy educational experience'. Australian Occupational Therapy Journal, 61 (1), 20-27 https://doi.org/10.1111/1440-1630.12037

Sullivan, T. and Finlayson, M. (2000) 'Role emerging fieldwork: The University of Manitoba approach'. OT Now, May/June, 13-24

Thew, M., Edwards, M., Baptiste, S., and Molineux, M. (eds.) (2011) Role Emerging Occupational Therapy: Maximising Occupation-Focused Practice. Chichester, UK: Wiley-Blackwell https://doi.org/10.1002/9781444340006

Thomas, Y., and Rodger, S. (2011) 'Successful role emerging placements: It is all in the preparation'. in: Role Emerging Occupational Therapy: Maximising OccupationFocused Practice. ed. by Thew, M., Edwards, M., Baptiste, S., and Molineux, M. Chichester, UK: Wiley-Blackwell 39-53 https://doi.org/10.1002/9781444340006.ch3 
United Nations, Department of Economic and Social Affairs, Population Division (2015) World Population Ageing 2015 (ST/ESA/SER.A/390). New York: United Nations

Williams, R., Lusk, S., and Kline, N. (1986) 'Knowledge of aging and cognitive styles in baccalaureate nursing students'. The Gerontologist, 26 545-550

https://doi.org/10.1093/geront/26.5.545 